\title{
Do markets behave as expected? Empirical test using both implied volatility and futures prices for the Taiwan Stock Market
}

\author{
A.-P. Chen, H.-Y. Chiu, C.-C. Sheng \& Y.-H. Huang \\ Institute of Information Management, University of National Chiao Tung, \\ Taiwan, Republic of China
}

\begin{abstract}
This study adopts derivative pricing as an indicator of market expectations, with those results suggesting that general investors can use market expectations to predict the final settlement value of underlying assets. Most investment textbooks note that one of the major functions of futures is price discovery. Similarly, the implied volatility associated with option prices can be used to discover the volatility of the underlying asset. This study combines futures price and implied volatility to establish a probability space of market expectations regarding the final settlement value of the underlying asset, and verifies this probability space using empirical data from the Taiwan stock market. The verification results suggest that market expectations closely reflect the actual behavior of the final settlement value of the underlying asset, and thus provide a practical perspective on future price behavior. According to this study, investors can easily estimate underlying asset behavior based on the behavior of the related futures and options and without incurring significant measurement error, which can be helpful in risk management and planning investment strategies.
\end{abstract}

Keywords: forecasting, market expectation, implied volatility, futures, probability space.

\section{Introduction}

Most financial texts confer that the futures markets aggregate diverse information and expectations regarding the future prices of underlying assets, and thus provide a common reference price which is known as the price 
discovery function of futures. For example, three topics are commonly discussed in relation to the price discovery function of futures. The first topic deals with the lead-lag relationship and information transmission between the prices of national markets, or between different securities [6, 21]. The second topic involves the discussion of volatility spillover, since volatility is also a source of information $[12,19]$. The third topic relates to the phenomenon of information transmission between stock index and index futures markets [7, 9, 14, 15, 18].

Similar to futures markets, options markets may also provide a common reference of subsequent real volatility (RV) by calculating the implied volatilities (IV). Early research on the predictive capability of IV found that IV explains variation in future volatilities better than that in historical volatilities (HV). For example, Lantane and Rendleman [17] found that actual option valuations were better explained by actual volatility over the life of the contract than by historical volatility. Chiras and Manaster [8] also tried to compare the predictive power of IV and HV using the CBOE data, and found that IV has superior forecasting power to HV. However, subsequent studies applying time serious methodologies to study the predictive power of implied volatility have yielded mixed results. Some studies have found that IV is a poor method of forecasting subsequent RV, while other studies have found that IV is a good method of forecasting RV. For example, Canina and Figlewski [5] found virtually no relation between the IV and subsequent RV throughout the remaining life of S\&P 100 index options before maturity date. Moreover, Day and Lewis [11] and Lamoureux and Lastrapes [16] both found that GARCH associated with $\mathrm{HV}$ is better able to predict RV than IV. Meanwhile, other studies have found that IVs provide reasonably good information on the subsequent RVs of the underlying asset. For example, Harvey and Whaley [4] tested and rejected the hypothesis that volatility changes are unpredictable. Blair et al. [2] indicated that IV index provides good forecasts for S\&P 100 index. Moreover, Fleming [13] examined the performance of the implied volatility of the S\&P 100 for forecasting future stock market volatility, and found that although IV has an upward bias but it contains relevant information regarding future volatility.

Although the volatility discovery function of options yields mixed results, the mutual influences between options and futures cannot be ignored where futures and options contracts exist for the same underlying asset. Put-call parity is a strong arbitrage relation, first identified by Stoll [20], that exists between the prices of European put and call options that share same underlying asset with the same strike and expiry, and the combination of options can create positions that are equivalent to holding the underlying itself. Accordingly, the call price $C$, put price $P$, strike price $K$, and underlying stock price $\mathrm{S}$ must satisfy the following equation: $C-P=S-P V$ (Dividends) $-K e^{(-r T)}$, where $T$ denotes the option holding period, $r$ represents a continuously compounded interest rate and $P V$ (Dividends) is the present value of the dividends received by the stock owner during the holding period. Although put-call parity identifies the relationship between options and underlying assets, in real world scenarios it is difficult to duplicate a stock index with limited stock positions but such an index can be easily duplicated using the related futures. Given the simultaneous existence of 
both options and futures contracts for the same underlying securities and with the same strike and expiry, put-call parity becomes $C-P=F P-P V$ (Dividends) $-K$ $e^{(-r T)}$ where FP is the futures price of the relative underlying asset. Thus, it is necessary to verify that the combination of futures and options prices reflects market expectations regarding the final settlement value behaviours of the underlying asset. This study examines futures and options prices of the Taiwan Stock Exchange Capitalization Weighted Stock Index and finds that the market expectations can display the real final settlement value via a nearly normal distribution in which the mean equals the futures price and the standard deviation equals the implied volatility.

\section{Determining market expectations using futures and options}

Market expectations are difficult to observe directly. However, market expectations can be estimated using derivatives because derivatives prices reflect the expected behaviours of the final settlement value of the underlying asset on maturity. For example, if the spot price of a particular asset is $\$ 100$ and its futures price is $\$ 101$, the market expects the final settlement value of the underlying asset to be $\$ 1$ higher than its current price. In this case, the noarbitrage principle holds that investors will sell the futures and simultaneously buy the spot to perform risk-less arbitrage. Consequently, the spot and futures prices will be equal, thus weakening the price discovery function of futures. Although the no-arbitrage principle holds for most real assets, virtual assets such as stock indexes may violate this principle because of the difficulty of generating a reasonable position that precisely mirrors the behaviour of the index using limited stocks combinations in order to perform risk-less hedge. Thus, the prices of the stock index and its associated futures do not always equal to each other in the real world even after discounting the forward looking nature of futures. The price discovery function thus still holds for stock index futures.

Besides futures, options also provide information regarding market expectations, and Cox and Ross [10] established that the value of options is their expected return at maturity. Current markets widely adopt the Black-Scholes model [3] to calculate expected returns using the input variables of spot price $S$, exercise price $K$, risk-less interest rate $r$, time to maturity $t$ and volatility $\sigma$ of the underlying asset. The implied volatility (IV) can be calculated by including the option market price in the Black-Scholes model with fixed $(S, K, t, r)$. Being derived from market price, IV can be interpreted as the market expectations of volatility during the time to maturity of the underlying asset. Combining the futures price (FP) and IV can calculate a range of market expectations regarding the value of the underlying asset on maturity, with the central point $\mu$ located at FP and standard deviation $\sigma$ equalling the IV transformed into the scale of days to maturity $V_{t}$ as shown in Figure 1.

Assuming that FP and IV form a market expectation probability space regarding the final settlement value, this study verifies the accuracy of such market expectations in the following section using four years of historical data from the Taiwanese stock market. 
Market Expected Possibility Space

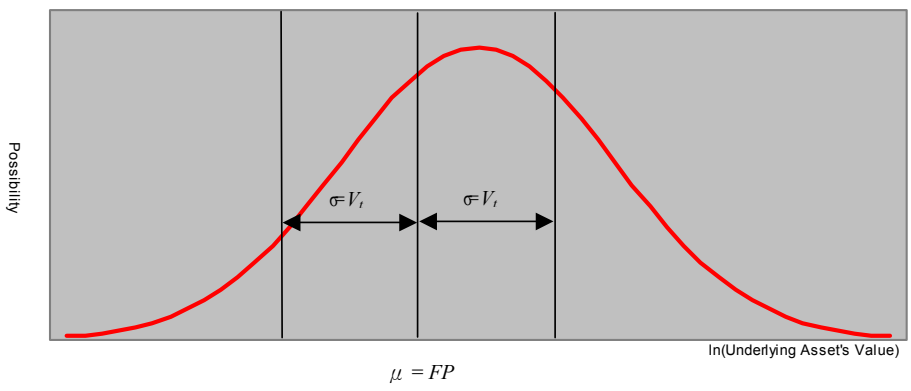

Figure 1: $\quad$ Market expected possibility space generated by $\left(F V, V_{t}\right)$.

\section{Empirical test of market expectations}

This section outlines the verification procedure and results of testing the accuracy of market expectations formed by FP and IV. The notations used in this study are shown as Table1.

Table 1: $\quad$ Notations list.

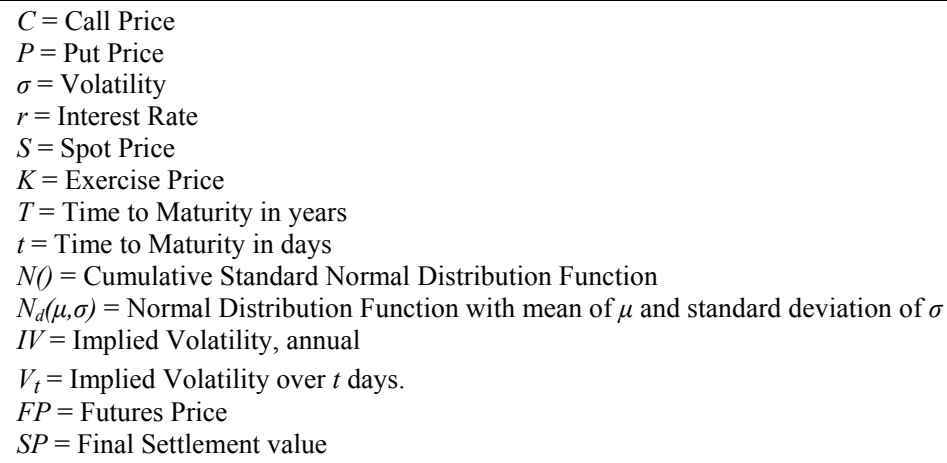

The first step in generating a market expectation probability space is calculating the implied volatilities. Most studies on the observed market prices of various options based on a single underlying asset estimated the volatility using at-the-money or near-the-money options since these instruments are more sensitive to volatility changes and least susceptible to the influence of the bid-ask spread [22]. Notably, Beckers [1], Wiggins [23] and Canina and Figlewski [5] indicated that near-the-money options are better predictors of future real volatility than IVs of deep in or out of the money options. Thus, this study uses only the daily close price of near-the-money nearby options contracts with the same underlying asset of the same strike and expiry for verification. 
According to the Black-Scholes model, the call price $C$ and put price $P$ of a European option can be calculated as follows:

$$
\begin{gathered}
C=S N\left(d_{1}\right)-K e^{-r T} N\left(d_{2}\right) \\
P=K e^{-r T} N\left(-d_{2}\right)-S N\left(-d_{1}\right) \\
d_{1}=\frac{\ln \left(\frac{S}{K}\right)+\left(r+\frac{\sigma^{2}}{2}\right) T}{\sigma \sqrt{T}} \\
d_{2}=\frac{\ln \left(\frac{S}{K}\right)+\left(r-\frac{\sigma^{2}}{2}\right) T}{\sigma \sqrt{T}}
\end{gathered}
$$

This study modified the method used to calculate implied volatility to yield an unbiased probability space. Traditionally, calculating an implied volatility (IV) requires solving (3.1) or (3.2) repeatedly using different trial values for the volatility input. However, the derived IV of a call option (3.1) rarely equals the value obtained from a put option (3.2) with the same exercise price, and thus most IV related studies only consider call or put options. However, with the relationship indicated by put-call parity, the FP, $C$ and $P$ of the same underlying with the same strike and expiry are tightly coupled, and a slight change in the price of one will immediately affect the price of the other two. Thus, to verify the possibility space created by FP and IV, this study combined put and call IVs to yield a single value IV, i.e., the union IV $\left(I V_{u}\right)$. Combining (3.1) and (3.2) can solve $I V_{u}$ using the following formula:

$$
C+P=S N\left(d_{1}\right)-K e^{-r T} N\left(d_{2}\right)+K e^{-r T} N\left(-d_{2}\right)-S N\left(-d_{1}\right)
$$

Let $\mathcal{O}_{c}=\left\{C_{1}, C_{2}, \ldots, C_{n}\right\}$ denote the historical near-the-money call option prices in time interval $\mathcal{I}$, while $\mathcal{O}_{p}=\left\{P_{1}, P_{2}, \ldots, P_{n}\right\}$ represents the historical near-themoney put options prices in $\mathcal{J}$ and $\mathcal{F}=\left\{F P_{1}, F P_{2}, \ldots, F P_{n}\right\}$ is the futures prices in $\mathcal{J}$. For the $i^{\text {th }}$ historical data in $\mathcal{J},\left(C_{i}, P_{i}, F P_{i}\right)$ is used to generate the $i^{\text {th }}$ sampling distribution space and the actual final settlement value of $\left(C_{i}, P_{i}\right)$ is $\mathrm{SP}_{i}$.

Considering the $i^{\text {th }}$ historical data in $\mathcal{J}$, substituting $\mathrm{C}_{i}$ and $\mathrm{P}_{i}$ into (3.5), the annual $I V_{u}$ of the $i^{\text {th }}$ day in $\mathcal{J}$ can be solved. Let $\boldsymbol{V}=\left\{V_{1}, V_{2}, \ldots, V_{n}\right\}$ denote the $\mathrm{IV}_{u}$ in $\mathcal{J}$. Furthermore, transfer the annual $\mathrm{IV}_{u}$ into the same scale as days to mature, and let $\mathrm{v}_{t}$ denote the union implied volatility of $\mathrm{t}$ days to mature:

$$
v_{t}=\sqrt{\frac{t \times V_{i}^{2}}{365}}
$$

Assume that $\mathrm{SP}_{i}$ and $\mathrm{FP}_{i}$ are the relative final settlement value and future price of the $i^{\text {th }}$ historical data in $\mathcal{J}$, then the actual SP is located at $d_{i}$ standard deviations of an $\mathrm{N}_{\mathrm{d}}(\mu, \sigma)=\mathrm{N}\left(F P_{i}, v_{t}\right)$ distribution space:

$$
d_{i}=\frac{\ln \left(\frac{S P_{i}}{F P_{i}}\right)}{v_{t}}
$$


Thus, for each historical record in $\mathcal{J}$ a $\boldsymbol{d}_{i}$ can be calculated, and collectively these $d_{i}$ form a sampling space of standard deviations $\mathfrak{D}=\left\{d_{1}, d_{2}, \ldots, d_{n}\right\}$. If the final settlement value follows the distribution of $\mathrm{N}_{d}(\mu, \sigma)=\mathrm{N}_{d}\left(F P_{i}, v_{t}\right)$ as expected by the market, the distribution of $\mathcal{D}$ will be a standard normal distribution, $\mathrm{N}_{d}(\mu, \sigma)=\mathrm{N}_{d}(0,1)$.

To confirm the accuracy of the market expectations of $(F P, I V)$, this study uses the option and futures prices of the Taiwan Stock Exchange Capitalization Weighted Stock Index (TAIEX) from 24/12/2001 to 30/12/2005 to test the results, $\mathfrak{J}=[24 / 12 / 2001,30 / 12 / 2005]$. The index values of TAIEX in $\mathcal{J}$ are demonstrated as Figure 2.

Daily values of Taiwan Stock Exchange Capitalization Weighted Stock Index

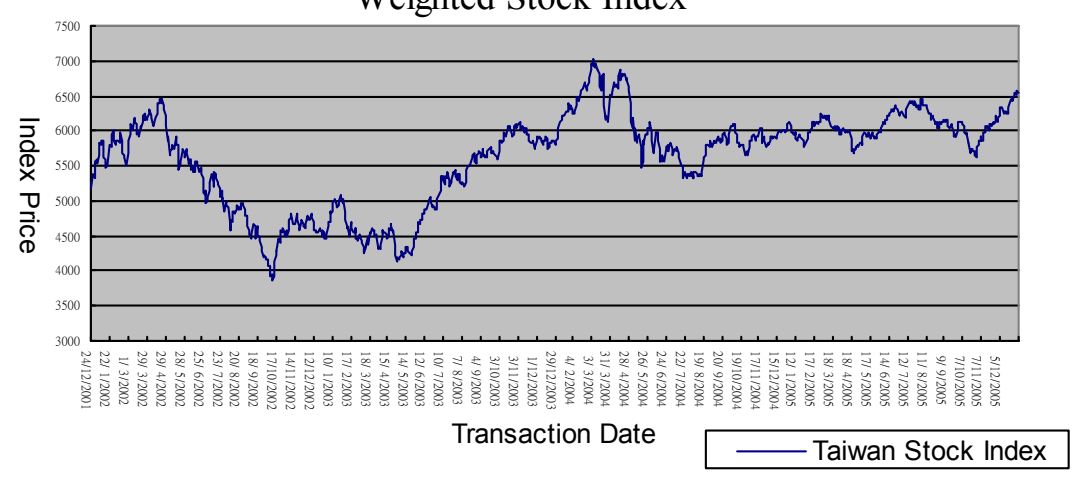

Figure 2: $\quad$ Stock index values in I.

The risk-less interest rate $r$ applied in this study is the monthly fixed deposit interest rate adopted by the Central Bank of Taiwan. The calculation results of $\mathscr{D}$ are collected in Figure 3.for comparison with the normal distribution $\mathrm{N}_{d}(0,1)$, and the mean, standard deviation, skewness and kurtosis of $\mathcal{D}$ are 0.0163 , $1.1109,-0.2920$ and 3.4500 , respectively.

Figure 3 exhibits that the distribution of $\mathscr{D}$ approximates that of $\mathrm{N}_{d}(0,1)$, and is skewed left and peaked compared to $\mathrm{N}_{d}(0.0163,1.1109)$ but slightly flatter and skewed right compared to $\mathrm{N}_{d}(0,1)$ also has thicker tails. That is, the actual final settlement values for Taiwan Stock Index futures and options roughly follow the market expectation formed by FP and IV, but have slightly larger volatilities. Another interesting observation is that two possibility peaks located at exactly +0.5 and -0.5 standard deviations. 


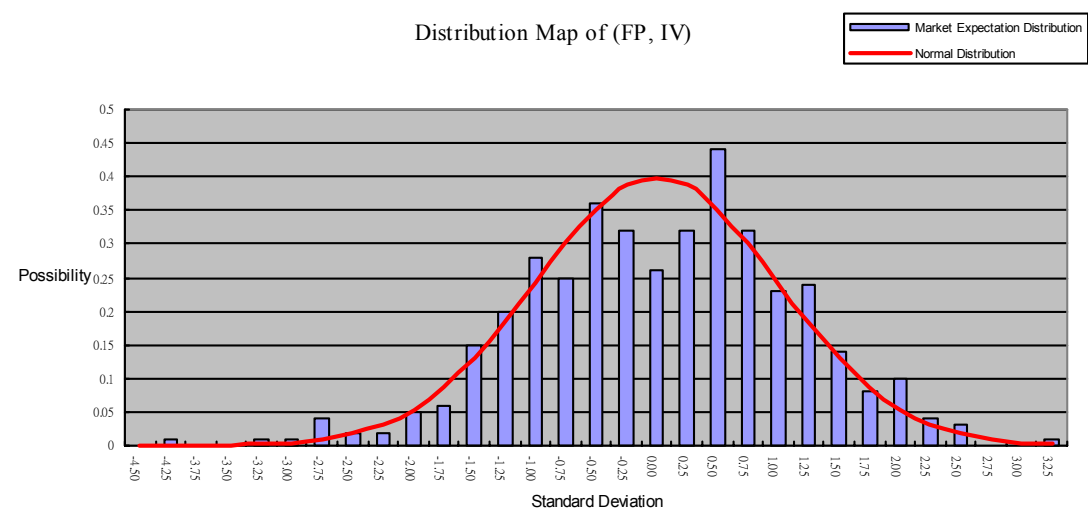

Figure 3: Market expectation distribution map of (FP, IV) compared to the normal distribution, $\mathrm{D}(\mu, \sigma$, skewness, kurtosis $)=\mathrm{D}(0.0163,1.1109$, $0.2920,3.4500)$.

Distribution Map of (S, IV)

Market Expectation Distribution

Normal Distribution

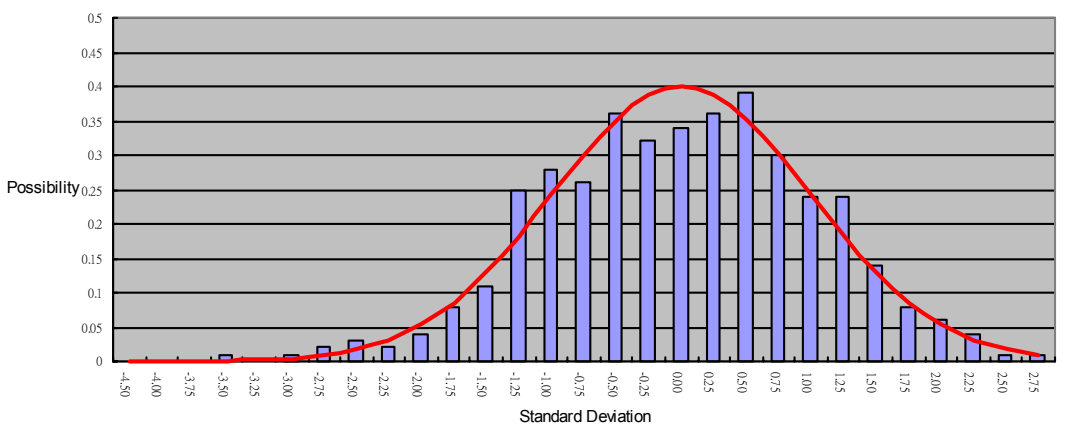

Figure 4: The market expectation distribution map of (S, IV) compared to the normal distribution, $\mathrm{D}^{\prime}(\mu, \sigma$, skewness, kurtosis $)=\mathrm{D}^{\prime}(0.0050$, $1.0609,-0.3102,3.4146)$.

Using the closing price of the stock index rather than the FP in (3.7), another possibility space formed by IV only can be generated. Letting $\mathfrak{D}^{\prime}=\left\{d_{1}^{\prime}, d_{2}^{\prime}, \ldots, d_{n}^{\prime}\right\},(3.7)$ becomes:

$$
d^{\prime}{ }_{i}=\frac{\ln \left(\frac{S P_{i}}{S_{i}}\right)}{v_{t}}
$$

The computed results of $\mathfrak{D}^{\prime}$ in $\mathcal{J}$ are summarized in Figure 4. Compared to the normal distribution $\mathrm{N}_{d}(0,1)$, the mean, standard deviation, skewness and kurtosis of $\mathfrak{D}^{\prime}$ are $0.0050,1.0609,-0.3102$ and 3.4146 , respectively. 
Figure 4 displays that the distribution of $\mathfrak{D}^{\prime}$ resembles $\mathrm{N}_{d}(0,1)$ more closely than does that of $\mathscr{D}$ and is skewed left and peaked compared to $\mathrm{N}_{d}(0.0050,1.0609)$, but slightly flatter and skewed right compared to $\mathrm{N}_{d}(0,1)$ and also has thicker tails. Comparing $\mathfrak{D}$ and $\mathfrak{D}^{\prime}$, the actual final settlement values of Taiwan Stock Index futures and options roughly follow the market expectations formed by FP and IV but more closely follow the expectations of S and IV.

The cumulative possibility distributions from intervals $\pm \sigma$ to $\pm 3 \sigma$ of the normal distribution, $\mathscr{D}$ and $\mathfrak{D}^{\prime}$, are listed as Table 2.

Table 2: Cumulative possibility distributions.

\begin{tabular}{|l|l|r|r|r|}
\cline { 3 - 5 } \multicolumn{2}{c|}{} & \multicolumn{1}{c|}{$\pm \sigma$} & \multicolumn{1}{c|}{ $\pm 2 \sigma$} & \multicolumn{1}{c|}{ $\pm 3 \sigma$} \\
\hline \multirow{2}{*}{ Normal Distribution } & Value & 0.6827 & 0.9545 & 0.9973 \\
\hline \multirow{2}{*}{ Market Expectation Distribution of $\mathcal{D}(\mathrm{FP}, \mathrm{IV})$} & Value & 0.632 & 0.932 & 0.989 \\
\cline { 2 - 5 } & Delta $(\%)$ & -7.4264 & -2.3573 & -0.8322 \\
\hline \multirow{2}{*}{ Market Expectation Distribution of $\mathcal{D}(\mathrm{S}, \mathrm{IV})$} & Value & 0.657 & 0.941 & 0.994 \\
\cline { 2 - 5 } & Delta (\%) & -3.7645 & -1.4144 & -0.3309 \\
\hline
\end{tabular}

Table 2 reveals that the cumulative possibility of $\mathscr{D}$ is smaller than the normal distribution, being approximately $7.43 \%$ in the plus minus one standard deviation, and $0.83 \%$ smaller in $\pm 3 \sigma . \mathscr{D}^{\prime}$ is even closer to the normal distribution in the testing example presented here, but both $\mathscr{D}$ and $\mathfrak{D}^{\prime}$ clearly demonstrate that the option price is slightly under estimated. However, after calculated the investment profits during the sampling period, the result indicates that the market maker only suffers 2\% loss in four years. Observing Figure 3, Figure 4 and Table 2 reveals that the final settlement value of the stock index roughly meets market expectations as indicated by both the futures and options. This conclusion also indicates that investors can expect the final settlement value of a stock index to equal the futures price, with a standard deviation equalling the implied volatility derived from option price. Based on this conclusion, investors can expect the performance of their stock positions to roughly follow that of holding both futures and options combinations, but most likely with an expectation bias of \pm 0.5 implied volatilities. Another observation of this study also suggests that (S, IV) combinations more closely reflect stock index price behaviour than (FP, IV) combinations; that is, applying options only may achieve better risk management performance than using combinations of both options and futures.

\section{Conclusions}

This study used derivatives prices to indicate market expectations and found that the final settlement value of the stock index moves roughly in accordance with market expectations. Although market expectations cannot precisely forecast the final settlement value of the underlying assets, general investors can easily adopt 
the futures price as the expected final settlement value, with standard deviation equaling the near-the-money implied volatility derived from option prices.

Another interesting finding was that market participants tend to slightly under estimate actual volatility in the Taiwanese stock market. Two possible explanations for this finding exist. The first explanation may be the pricing error of the naïve Black-Scholes model, which constantly underestimates the near-themoney option price. However, this study finds that option market makers suffer only a $2 \%$ loss during the four sample years, indicating that the Black-Scholes model only insignificantly underestimates the near-the-money option price. The second explanation is that general market participants tend to be conservative in anticipating stock index volatility and may slightly under-estimate option prices. The final and most interesting finding of this study was that overall market expectations exhibit two peaks, located at the +0.5 and -0.5 standard deviations. This phenomenon is particularly clear for the market expectations regarding FP and IV, and thus further research is required to explore this market behavior and its influence on general investors.

\section{References}

[1] Beckers, S., Standard Deviations Implied in Option Prices as Predictors of Future Stock Price Variability, Journal of Banking and Finance, Vol. 5, No. 3, 1981, pp. 363-381, 1981.

[2] Bevan J. Blair, Ser-Huang Poon, Stephen J., Taylor. Forecasting S\&P 100 volatility: the incremental information content of implied volatilities and high-frequency index returns. Journal of Econometric, 105, pp. 5-26, 2001.

[3] Black, F., Scholes, M., The pricing of options and corporate liabilities. Journal of Political Economy, 81, pp. 637-654, 1973.

[4] Campbell R. Harvey and Robert E. Whaley, Market volatility prediction and the efficiency of the S\&P 100 index option market, Journal of Financial Economics 31, pp. 43-73, 1992.

[5] Canina, L., Figlewski, S., The informational content of implied volatility. Review of Financial Studies 6, pp. 659-681, 1993.

[6] Chan, K., A further analysis of the lead-lag relationship between the cash market and stock index futures market. Review of Financial Studies, 5, pp.123-152, 1992.

[7] Chan, K., Chan, K. C., \& Karolyi, G. A., Intraday volatility in the stock index and stock index futures markets. Review of Financial Studies, 4, pp. 657-684, 1991.

[8] Chiras, D.P., Manaster, S., The information content of option prices and a test of market efficiency. Journal of Financial Economics, 6 (2/3), pp. 213-234, 1978.

[9] Chu, Q. C., Hsieh, W. G., Tse, Y., Price discovery on the S\&P 500 index markets: An analysis of spot index, index futures, and SPDRs. International Review of Financial Analysis, 8, pp.21-34, 1999. 
[10] Cox, John C. and Stephen A. Ross, The valuation of options for alternative stochastic processes, Journal of Financial Economics, 3, pp.145-166, 1976.

[11] Day, T., Lewis, C., Stock market volatility and the information content of stock index options. Journal of Econometrics, 52, pp.267-287, 1992.

[12] French, K. R., \& Roll, R., Stock return variances: The arrival of information and the reaction of traders. Journal of Financial Economics, 17, pp.5-26, 1986.

[13] Jeff Fleming, The quality of market volatility forecasts implied by S\&P 100 index option prices. Journal of Empirical Finance, 5, pp. 317-345, 1998.

[14] Kawaller, I.G. \& Koch, P.D. \& Koch T.W., The Temporal Price Relationship between S\&P 500 Futures and the S\&P 500 index. Journal of Finance, 42, pp.1309-1329, 1987.

[15] Koutmos, G., \& Tucker, M., Temporal relationships and dynamic interactions between spot and futures stock markets. Journal of Futures Markets, 16, pp.55-69, 1996.

[16] Lamoureux, C.G., Lastrapes, W., Forecasting stock return variance: towards understanding stochastic implied volatility. Review of Financial Studies 6, pp.293-326, 1993.

[17] Latane, H., Rendleman, R., Standard deviation of stock price ratios implied in option prices. Journal of Finance, 31, pp.369-381, 1976.

[18] Raymond W So, Yiuman Tse, Price Discovery in the HANG SENG INDEX MARKETS: index, futures, and the tracker fund. The Journal of Futures Markets. Hoboken, Sep 2004.Vol.24, Iss. 9; pp. 887, 2004.

[19] Ross, S., Information and volatility: The no-arbitrage martingale approach to timing and resolution irrelevancy. Journal of Finance, 44, pp.1-17, 1989.

[20] Stoll, Hans R., The relationship between put and call option prices, Journal of Finance, 23, pp.801-824, 1969.

[21] Stoll, H. R., Whaley, R. E., The dynamics of stock index and stock index futures returns. Journal of Financial and Quantitative Analysis, 25, pp.441-468, 1990.

[22] Whaley, Robert, Valuation of American Call Options on Dividend-Paying Stocks: Empirical Tests. Journal of Financial Economics, 10, pp. 29-58, 1982.

[23] Wiggins, J., Option values under stochastic volatility: Theory and empirical estimates, Journal of Financial Economics, 19, pp.351-372, 1987. 